\title{
Effects of ophiopogonin $B$ on the proliferation and apoptosis of SGC-7901 human gastric cancer cells
}

\author{
WEIYUE ZHANG ${ }^{1}$, QIAOYAN ZHANG ${ }^{2}$, YIPING JIANG ${ }^{2},{\text { FENG } \text { LI }^{1} \text { and HAILIANG XIN }}^{2}$ \\ ${ }^{1}$ School of Preclinical Medicine, Beijing University of Chinese Medicine, Beijing 100029; \\ ${ }^{2}$ Department of Pharmacognosy, School of Pharmacy, Second Military Medical University, Shanghai 200433, P.R. China
}

Received April 15, 2015; Accepted February 24, 2016

DOI: $10.3892 / \mathrm{mmr} .2016 .5198$

\begin{abstract}
Ophiopogonin B (OP-B) is a bioactive component of Radix Ophiopogon japonicus, which is often used in traditional Chinese medicine to treat cancer. The present study aimed to investigate the antitumor activity of OP-B in gastric cancer. Cell Counting kit-8, flow cytometry with Annexin V-fluorescein isothiocyanate, Hoechst staining, mitochondrial membrane potential (MMP) detection, and reactive oxygen species (ROS) assay were used to detect the biological function of SGC-7901 gastric cancer cells. The results demonstrated that high concentrations of OP-B (5, 10 and $20 \mu \mathrm{mol} / \mathrm{l})$ exerted potent antiproliferative effects on SGC-7901 cells in a dose-dependent manner. Furthermore, apoptotic rates were increased and cell morphology was altered following treatment with OP-B. In addition, OP-B-induced apoptosis of SGC-7901 cells was associated with loss of MMP and increased ROS generation. Western blotting indicated that treatment with OP-B increased the protein expression levels of caspase-3 and B-cell lymphoma 2 (Bcl-2)-associated X protein, whereas the expression levels of $\mathrm{Bcl}-2$ and the phosphorylation levels of extracellular signal-regulated kinases $1 / 2$ and c-Jun N-terminal kinases $1 / 2$ were decreased. These results suggest that OP-B may be considered a potential inhibitor of gastric cancer progression, and may be used as an alternative compound for its treatment.
\end{abstract}

\section{Introduction}

Gastric cancer (GC) is one of the most common cancers of the alimentary tract (1). GC is a major malignancy that

Correspondence to: Dr Hailiang Xin, Department of Pharmacognosy, School of Pharmacy, Second Military Medical University, 325 Guo-He Road, Shanghai 200433, P.R. China

E-mail: hailiangxin00@163.com

Dr Feng Li, School of Preclinical Medicine, Beijing University of Chinese Medicine, 11 Bei Sanhuan Donglu, Chaoyang, Beijing 100029, P.R. China

E-mail: fengli202@163.com

Key words: gastric cancer, ophiopogonin B, antitumor, apoptosis seriously affects patient health and is associated with a high rate of mortality; with prevalence in men double that in women (2). Research regarding the development of drugs for the treatment of GC and its complications has recently gained attention. Chemotherapy is one of major therapeutic methods for the treatment of cancer; however, cancer gradually evolves resistance to chemotherapeutic reagents (3). Therefore, the identification of novel therapeutic strategies is essential to improve the clinical management of patients with GC. The search for novel therapies has recently focused on several plants used in traditional medicine (4-6).

For centuries, traditional Chinese medicine has been used to treat cancer (7). The plant Ophiopogon japonicus (Thunb.) Ker-Gawl is an evergreen perennial medicinal herb, which has been widely used in Southeast Asia to treat disease for thousands of years $(8,9)$. O. japonicus contains the following active ingredients: Saponins, polysaccharides, and homoisoflavonoids (10). This plant has been reported to exert pharmacological effects, including cardioprotective, diuretic and antibacterial activities (11). Ophiopogonin B (OP-B), which is isolated from the traditional Chinese herb Radix $O$.japonicus, has been revealed to exert anticancer effects in human non-small cell lung cancer and cervical cancer $(12,13)$. However, the role of OP-B in GC has yet to be explored.

The present study aimed to investigate the anticancer effects of OP-B on cell proliferation, apoptosis, mitochondrial membrane potential (MMP) and reactive oxygen species (ROS) in the SGC-7901 GC cell line. In addition, the expression levels of apoptosis-associated proteins were detected, in order to explore the mechanisms underlying the effects of OP-B.

\section{Materials and methods}

Cell culture and treatment. The SGC-7901 human GC cell line was purchased from the Cell Bank of Chinese Academy of Sciences (Shanghai, China). The cells were cultured in RPMI 1640 medium (Hyclone; GE Healthcare Life Sciences, Logan, UT, USA) supplemented with $10 \%$ fetal bovine serum, penicillin $(100 \mathrm{IU} / \mathrm{ml})$ and streptomycin $(100 \mathrm{mg} / \mathrm{ml})(\mathrm{Gibco}$; Thermo Fisher Scientific, Inc., Waltham, MA, USA) at $37^{\circ} \mathrm{C}$ in a humidified atmosphere containing $5 \% \mathrm{CO}_{2}$. Cells in the logarithmic phase were used in the subsequent experiments. 
Cell viability assay. To detect cell viability following exposure to various concentrations $(0,5,10$ and $20 \mathrm{mmol} / \mathrm{l})$ of OP-B (Jrdun Biotechnology Corp., New York, NY, USA), $100 \mu 1$ SGC-7901 cells $\left(5 \times 10^{4} / \mathrm{ml}\right)$ were seeded in 96 -well plates and were cultured for $0,12,24,48$ and $72 \mathrm{~h}$ at $37^{\circ} \mathrm{C}$. Subsequently, $100 \mu \mathrm{l}$ serum-free Dulbecco's modified Eagle's medium (Hyclone; GE Healthcare Life Sciences) containing 10\% Cell Counting kit (CCK)-8 reagents (v/v) (Dojin Laboratories, Kumamoto, Japan) was added to each well, and the cells were cultured for $1 \mathrm{~h}$ in a $5 \% \mathrm{CO}_{2}$ atmosphere at $37^{\circ} \mathrm{C}$. Optical density was then measured at $450 \mathrm{~nm}$ using a Model 550 microplate reader (Bio-Rad Laboratories, Inc., Hercules, CA, USA).

Cell apoptosis assay. Cells were seeded at a density of $5 \times 10^{5}$ cells/well in 6-well plates, following treatment with OP-B $(0,5,10$ and $20 \mu \mathrm{mol} / \mathrm{l})$. The cells were subsequently stained using an Annexin V-fluorescein isothiocyanate (FITC)/propidium iodide kit (BD Biosciences, Franklin Lakes, NJ, USA). Staining was performed according to the manufacturer's protocol. Apoptosis of SGC-7091 cells was determined using a FACSCalibur flow cytometer (BD Biosciences, Franklin Lakes, NJ, USA).

Hoechst staining. Cells were seeded on a 6-well plate at $5 \times 10^{5}$ cells/well and were treated with OP-B $(0,5,10$ and $20 \mu \mathrm{mol} / \mathrm{l})$. Subsequently, attached cells were washed with phosphate-buffered saline (PBS) and were incubated with $10 \mu \mathrm{g} / \mathrm{ml}$ Hoechst 33342 staining solution (Sigma-Aldrich, St. Louis, MO, USA) for $10 \mathrm{~min}$. Following the incubation, cells were washed with PBS and anti-fade mounting medium was added. Apoptosis, as determined by condensed and fragmented nuclei (14), was observed under an RX-DA fluorescence microscope (Leica Microsystems $\mathrm{GmbH}$, Wetzlar, Germany).

MMP detection. Rhodamine-123 (Rho-123) dye (Sigma-Aldrich) was used to detect alterations in MMP. Cells $\left(1 \times 10^{6} / \mathrm{ml}\right)$ were cultured in a $24-w e l l$ plate. After a period of exposure to various concentrations of OP-B, cells were washed with PBS, incubated with Rho-123 (100 nM), and were subsequently subjected to flow cytometry.

Detection of ROS. ROS generation was assessed by flow cytometry (15). Briefly, cells $\left(5 \times 10^{4} /\right.$ well) were cultured, washed with PBS and were re-suspended in complete medium. Subsequently, the cells were incubated with $50 \mu \mathrm{M}$ DCFH-DA (Vigorous Biotechnology, Beijing, China). ROS fluorescence intensity was determined by flow cytometry at an excitation wavelength of $490 \mathrm{~nm}$ and an emission wavelength of $520 \mathrm{~nm}$.

Western blot analysis. Cells were harvested, and total proteins were extracted using ice-cold radioimmunoprecipitation assay buffer (Beyotime Institute of Biotechnology). Protein concentration was subsequently determined using a Bicinchoninic Acid Protein Assay reagent (Thermo Fisher Scientific, Inc.). Protein samples $(40 \mu \mathrm{g})$ were separated by sodium dodecyl sulfate-polyacrylamide gel electrophoresis, and were then transferred to nitrocellulose membranes. The membranes were

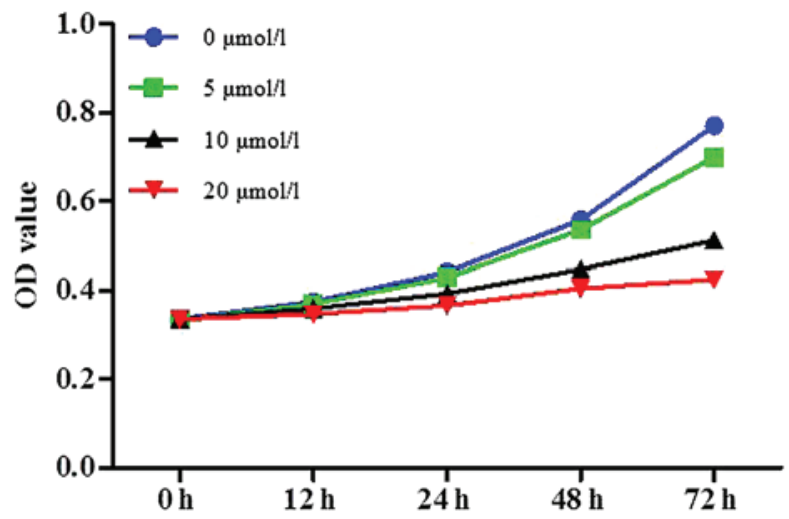

Figure 1. Ophiopogonin B (OP-B) inhibits proliferation of SGC-7901 cells The effects of various concentrations of OP-B $(0,5,10$ and $20 \mu \mathrm{mol} / 1)$ on the viability of SGC-7901 cells at 12, 24, 48 and $72 \mathrm{~h}$ were assessed by Cell Counting kit- 8 assay. Data are presented as the mean \pm standard deviation. OD, optical density.

blocked in $5 \%$ skim milk solution for $1 \mathrm{~h}$ at room temperature, then were incubated with rabbit antibodies against phosphorylated (p)-c-Jun N-terminal kinases (JNK)1/2 (dilution, 1:800; cat. no. 4668; monoclonal), JNK1/2 (dilution, 1:1,000; cat. no. 9252; polyclonal), p-extracellular signal-regulated kinases (ERK)1/2 (dilution, 1:1,000; cat. no. 4370; monoclonal), ERK1/2 (dilution, 1:1,000; cat. no. 4695; monoclonal) (all Cell Signaling Technology, Inc., Danvers, MA, USA), caspase-3 (dilution, 1:1,500; cat. no. ab32351; Abcam, Cambridge, UK; monoclonal), B-cell lymphoma 2 (Bcl-2; dilution, 1:400; cat. no. sc-492; polyclonal) and Bcl-2-associated X protein (Bax; dilution, 1:400; cat. no. sc-493; polyclonal) (both Santa Cruz Biotechnology, Inc., Dallas, TX, USA) overnight at $4^{\circ} \mathrm{C}$. This was followed by incubation with a horseradish peroxidase-conjugated goat anti-rabbit secondary antibody (dilution, 1:1,000; cat. no. A0208; Beyotime Institute of Biotechnology, Haimen, China) for $1 \mathrm{~h}$ at room temperature. Rabbit anti-glyceraldehyde 3-phosphate dehydrogenase (dilution, 1:1,500; cat. no. 5471; monoclonal) was used as the loading control. The blots were visualized using enhanced chemiluminescence (EMD Millipore, Billerica, MA, USA) and analyzed with ImageJ v. 1.49 software (imagej.nih.gov/ij). Western blots presented in the figures are representative of three independent experiments.

Statistical analysis. All data are presented as the mean \pm standard deviation from three determinations. Data were analyzed with two-tailed Student's t-tests for comparison with the $0 \mu \mathrm{mol}$ group. For statistical analysis, GraphPad Prism 5.0 (GraphPad Software, Inc., San Diego, CA, USA) was used. P<0.05 was considered to indicate a statistically significant difference.

\section{Results}

Effects of OP-B on proliferation of SGC-7901 cells. SGC-7901 cells were treated with various concentrations of OP-B for 0 , $12,24,48$ and $72 \mathrm{~h}$, and the CCK-8 assay was used to measure cell proliferation. As shown in Fig. 1, treatment with OP-B was able to inhibit GC cell proliferation in a dose-dependent manner. 
$\mathbf{A}$
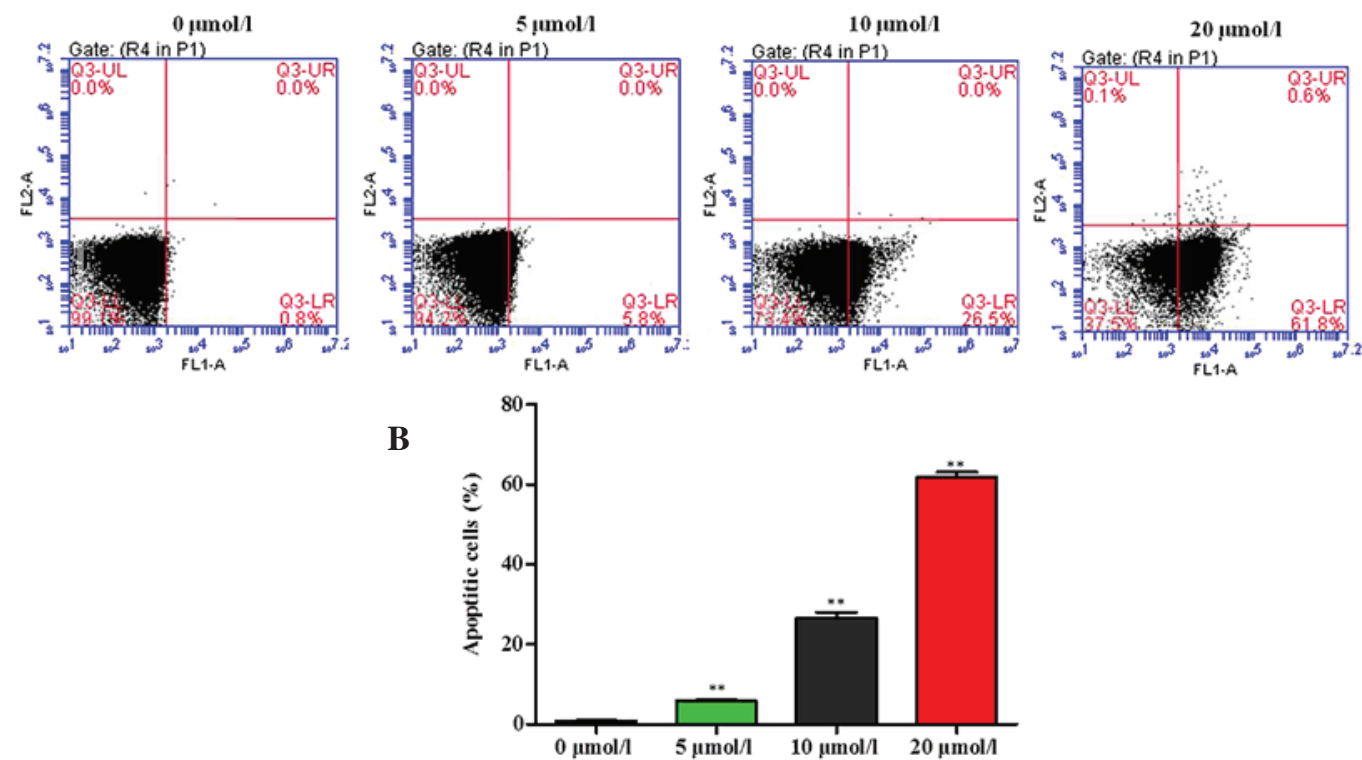

Figure 2. Ophiopogonin B (OP-B) induces apoptosis of SGC-7901 cells. Cells were incubated with 0, 5, 10 or $20 \mu$ mol/1 OP-B. (A) Representative flow cytometric results. (B) Percentage of apoptotic cells. Data are presented as the mean \pm standard deviation. ${ }^{* *} \mathrm{P}<0.01 \mathrm{vs} .0 \mu \mathrm{mol} / 1$.
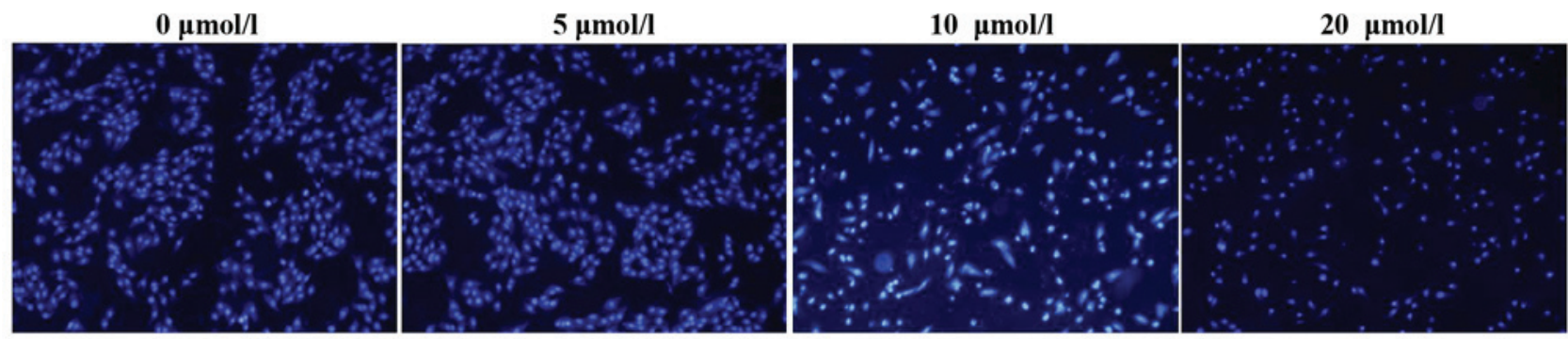

Figure 3. Ophiopogonin B (OP-B) induces morphological alterations to SGC-7901 cells. Cells were incubated with 0, 5, 10 and $20 \mu$ mol/1 OP-B, were fixed and stained with Hoechst 33342, and were observed under a fluorescent microscope. Cells treated with OP-B exhibited condensed chromatin and fragmented nuclei. Magnification, $\mathrm{x} 200$.

Effects of OP-B on the apoptosis of SGC-7901 cells. Three different concentrations of OP-B were used to treat SGC-7901 cells for $24 \mathrm{~h}$. Flow cytometric analysis of Annexin V-FITC staining demonstrated that OP-B significantly increased the apoptotic rate of SGC-7901 cells in a dose-dependent manner (Fig. 2).

Effects of OP-B on morphological alterations to SGC-7901 cells. To confirm that OP-B induced apoptosis, morphological alterations to SGC-7901 cells were observed following Hoechst 33342 staining. As shown in Fig. 3, following OP-B treatment, blue emission was much brighter than in the control cells, indicating the presence of apoptotic cells. In addition, condensed chromatin was detected in several of the OP-B-treated cells and apoptotic bodies had formed in some cells.

Effects of OP-B on MMP in SGC-7901 cells. To assess the effects of OP-B on alterations to the MMP in SGC-7901 cells, flow cytometry was conducted to detect the fluorescence intensity of Rho-123. As shown in Fig. 4, treatment of SGC-7901 cells with OP-B $(5,10$, and $20 \mu \mathrm{mol} / \mathrm{l})$ for $24 \mathrm{~h}$ resulted in a moderate depolarization of MMP in a dose-dependent manner.
Effects of OP-B on ROS generation in SGC-7901 cells. The fluorescent probe dichlorodihydrofluorescein diacetate was used to determine the levels of ROS generation in SGC-7901 cells. As shown in Fig. 5, SGC-7901 cells exposed to 5, 10, and $20 \mu \mathrm{mol} / 1 \mathrm{OP}-\mathrm{B}$ for $12 \mathrm{~h}$ exhibited a significant increase in the intracellular accumulation of ROS in a dose-dependent manner.

Western blotting results. To clarify the mechanism by which OP-B induced SGC-7901 cells apoptosis, the expression levels of apoptosis-associated proteins and the phosphorylation of kinases were determined by western blotting. As shown in Fig. 6A, treatment with OP-B for $6 \mathrm{~h}$ resulted in downregulation of the protein expression levels of $\mathrm{p}-\mathrm{JNK} 1 / 2$ and p-ERK1/2. Furthermore, following treatment with OP-B for $48 \mathrm{~h}$, protein expression levels of caspase- 3 and Bax were increased, whereas the expression levels of $\mathrm{Bcl}-2$ were downregulated (Fig. 6B).

\section{Discussion}

OP-B is a natural active compound extracted from the Chinese herbal medicine $O$. japonicus, which is widely used in clinical 

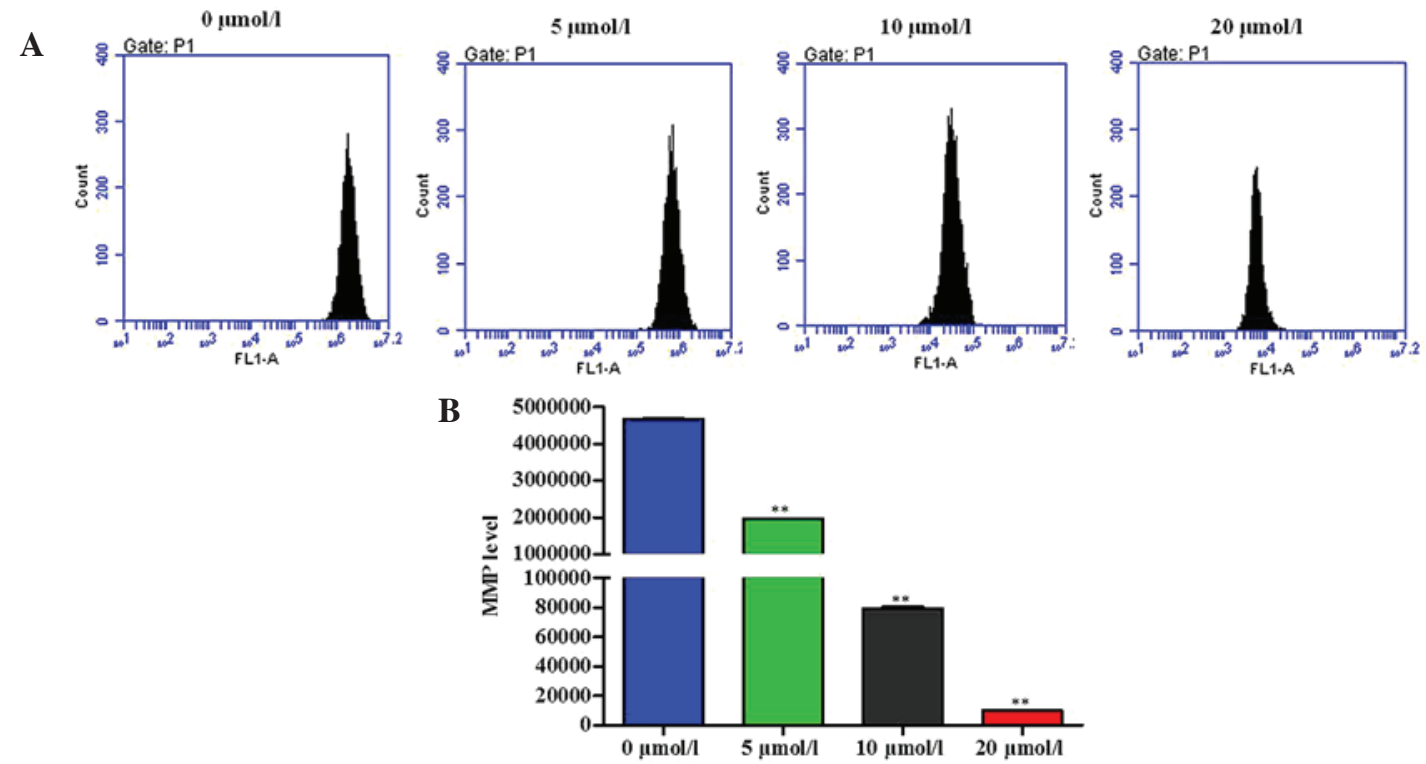

Figure 4. Ophiopogonin B (OP-B) decreases mitochondrial membrane potential (MMP) in SGC-7901 cells. Cells were treated with 0, 5, 10 and $20 \mu$ mol/l OP-B for $24 \mathrm{~h}$, and were then incubated with Rhodamine-123 and analyzed by flow cytometry. (A) Representative results. (B) Fluorescence intensity. Data are presented as the mean \pm standard deviation ${ }^{* *} \mathrm{P}<0.01 \mathrm{vs} .0 \mu \mathrm{mol} / \mathrm{l}$.
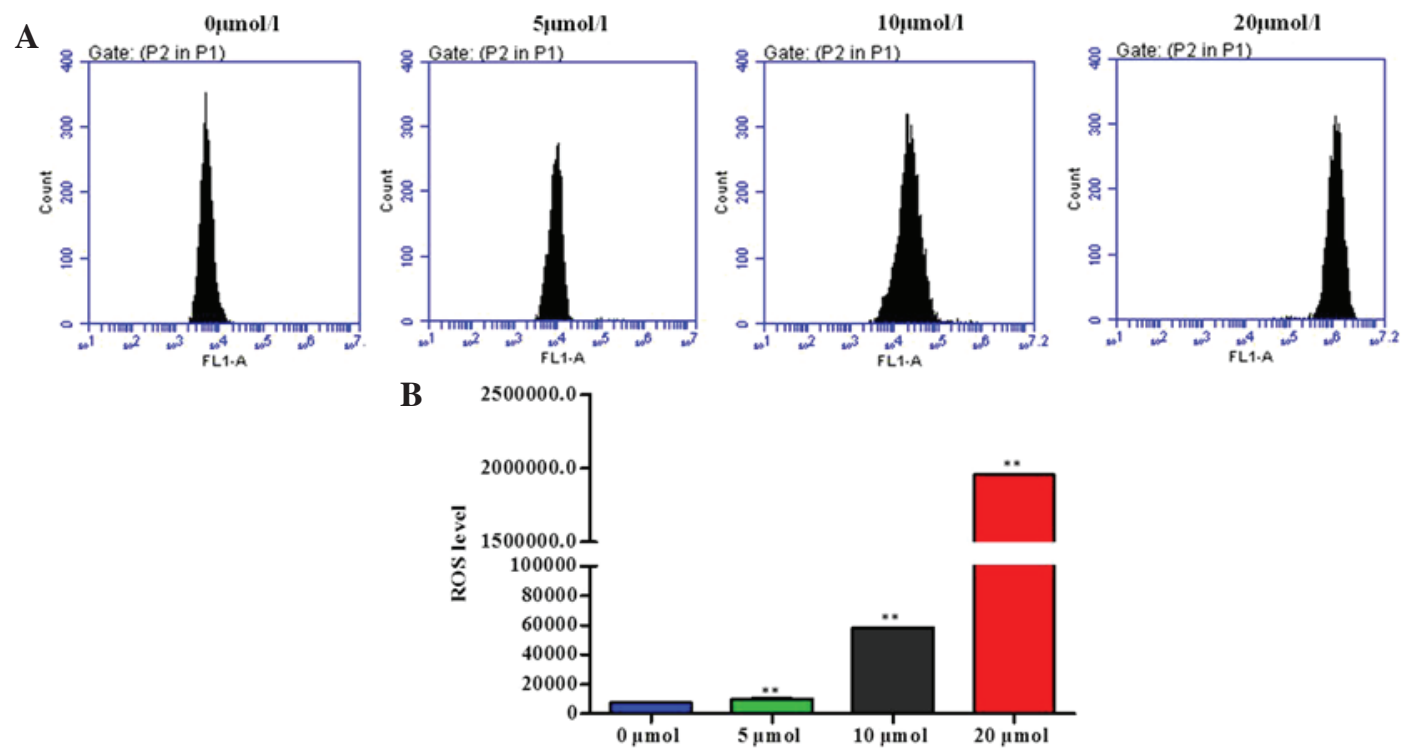

Figure 5. Ophiopogonin B (OP-B) increases the intracellular reactive oxygen species (ROS) generation in SGC-7901 cells. Cells were treated with 0, 5, 10 and $20 \mu \mathrm{mol} / \mathrm{l}$ OP-B for $24 \mathrm{~h}$. The fluorescence probe dichlorodihydrofluorescein diacetate was used to determine levels of ROS production. (A) Representative results. (B) ROS levels. Data are presented as the mean \pm standard deviation. ${ }^{* *} \mathrm{P}<0.01 \mathrm{vs} .0 \mu \mathrm{mol} / 1$.

Chinese medicine (16). The present study confirmed that high concentrations of OP-B were able to significantly inhibit the proliferation of SGC-7901 cells in a time- and dose-dependent manner. In addition, apoptotic rates were increased and cell morphology was altered following OP-B treatment, thus suggesting that induction of apoptosis may be the main mechanism underlying the antiproliferative effects of OP-B in SGC-7901 cells.

Apoptosis is a physiological process that leads to cell self-destruction. Dysregulation of this process is implicated in various diseases (17). Mitochondria are important cell organelles, the functions of which include respiration, oxygen metabolism and enzyme activity, and are associated with membrane permeability and MMP (18). Breakdown of the MMP is an early stage of the apoptotic process and precedes nuclear disintegration (19). In the present study, MMP fluorescence intensity was gradually reduced in response to high dose OP-B, thus suggesting that OP-B may induce cell apoptosis by decreasing MMP. Furthermore, the expression levels of apoptosis-associated proteins caspase- 3 and Bax were significantly increased, whereas the protein expression levels of Bcl2 were decreased.

ROS generation and subsequent oxidative stress have long been implicated in induction of cell apoptosis (20). 
A
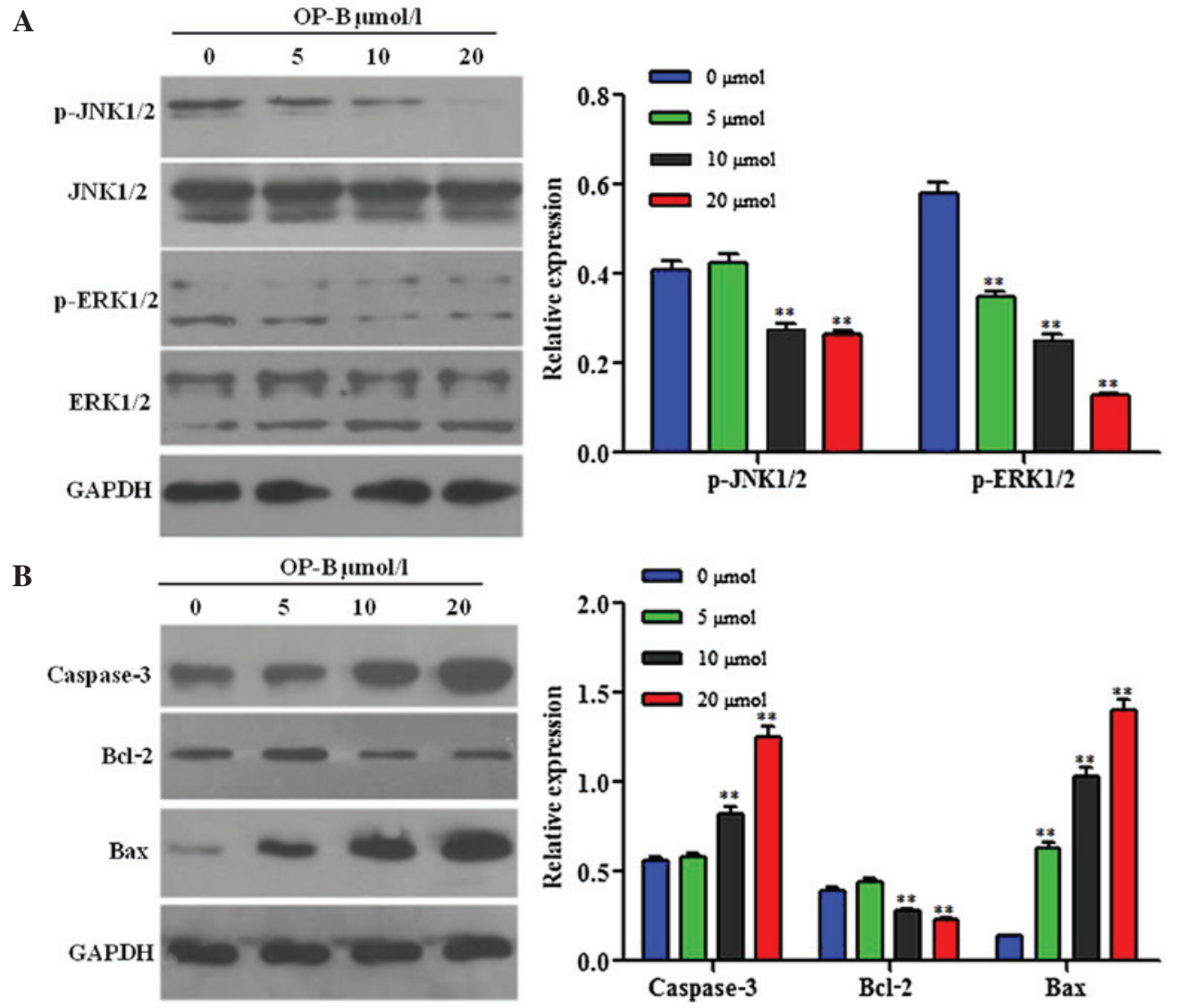

Figure 6. Effects of ophiopogonin B (OP-B) on protein expression, as detected by western blotting. (A) Cells were treated with 0,5, 10, $20 \mu \mathrm{mol} / 1 \mathrm{OP}-\mathrm{B}$ for $6 \mathrm{~h}$. The levels of phosphorylated (p)-c-Jun N-terminal kinases (JNK)1/2 and p-extracellular signal-regulated kinases (ERK)1/2 were decreased compared with in the control group. (B) Expression levels of apoptosis-associated proteins, caspase-3, B-cell lymphoma-2 (Bcl-2) and Bcl-2-associated X protein (Bax), were detected. Data are presented as the mean \pm standard deviation. ${ }^{* *} \mathrm{P}<0.01 \mathrm{vs.} 0 \mu \mathrm{mol} / 1$. GAPDH, glyceraldehyde 3-phosphate dehydrogenase.

Mitochondria have been identified as the major organelles in which ROS are generated (21). As expected, intracellular ROS levels were significantly increased when SGC-7901 cells were exposed to OP-B. The MAPK family comprises three main parallel pathways: ERK, JNK and p38. Previous studies have indicated that MAPK is an important pathway involved in cell proliferation and apoptosis (22-24). In the present study, the phosphorylation levels of JNK1/2 and ERK1/2 were increased in SGC-7901 cells following OP-B treatment. These results suggested that the anticancer mechanisms of OP-B may be associated with the JNK1/2 and ERK1/2 signaling pathways.

The pharmacological assays conducted in the present study suggested that OP-B may significantly decrease proliferation, and induce apoptosis of GC cells. In conclusion, OP-B may be considered a potential candidate agent for the treatment of GC. Further studies regarding the underlying mechanism of OP-B are currently ongoing.

\section{References}

1. Jemal A, Bray F, Center MM, Ferlay J, Ward E and Forman D: Global cancer statistics. CA Cancer J Clin 61: 69-90, 2011.

2. de Martel C, Forman D and Plummer M: Gastric cancer: Epidemiology and risk factors. Gastroenterol Clin North Am 42: 219-240, 2013.

3. Wong $\mathrm{H}$ and Yau T: Targeted therapy in the management of advanced gastric cancer: Are we making progress in the era of personalized medicine? Oncologist 17: 346-358, 2012.
4. Qi F, Li A, Inagaki Y, Gao J, Li J, Kokudo N, Li XK and Tang W: Chinese herbal medicines as adjuvant treatment during chemo-or radio-therapy for cancer. Biosci Trends 4: 297-307, 2010.

5. Li R, Chen WC, Wang WP, Tian WY and Zhang XG: Extraction, characterization of Astragalus polysaccharides and its immune modulating activities in rats with gastric cancer. Carbohydr Polym 78: 738-742, 2009.

6. Li X, Yang G, Li X, Zhang Y, Yang J, Chang J, Sun X, Zhou X, Guo Y, Xu Y, et al: Traditional Chinese medicine in cancer care: A review of controlled clinical studies published in Chinese. PLoS One 8: e60338, 2013.

7. Ling Y: Traditional Chinese medicine in the treatment of symptoms in patients with advanced cancer. Ann Palliat Med 2: 141-152, 2013.

8. Boyang Y and Guojun X: Studies on resource utilization of Chinese drug dwarf lilyturf (Ophiopogon japonicus). Zhongyao Maidong De Ziyuan Liyong Yanjiu 26: 205-210, 1995 (In Chinese).

9. Xiao P, Li DP and Yang SL: Modern Chinese materia medica. Chemical Industry Press 4: 253-272, 2002.

10. Kou J, Sun Y, Lin Y, Cheng Z, Zheng W, Yu B and Xu Q: Anti-inflammatory activities of aqueous extract from Radix Ophiopogon japonicus and its two constituents. Biol Pharm Bull 28: 1234-1238, 2005.

11. Lin X, Zhou QF and Xu D: Research progress of the pharmacological actions of ophiopogon root. Shang Hai Zhong Yi Yao Za Zhi She 38, 59-61, 2004 (In Chinese).

12. Chen M, Du Y, Qui M, Wang M, Chen K, Huang Z, Jiang M, Xiong F, Chen J, Zhou J, et al: Ophiopogonin B-induced autophagy in non-small cell lung cancer cells via inhibition of the PI3 K/Akt signaling pathway. Oncol Rep 29: 430-436, 2013.

13. Xu QJ, Hou LL, Hu GQ and Xie SQ: Molecular mechanism of ophiopogonin B induced cellular autophagy of human cervical cancer HeLa cells. Yao Xue Xue Bao 48: 855-859, 2013 (In Chinese). 
14. Kabeer FA, Sreedevi GB, Nair MS, Rajalekshmi DS, Gopalakrishnan LP, Kunjuraman S and Prathapan R: Antineoplastic effects of deoxyelephantopin, a sesquiterpene lactone from Elephantopus scaber, on lung adenocarcinoma (A549) cells. J Integr Med 11: 269-277, 2013.

15. Mondal J, Bishayee K, Panigrahi AK and Khuda-Bukhsh AR. Low doses of ethanolic extract of Boldo (Peumus boldus) can ameliorate toxicity generated by cisplatin in normal liver cells of mice in vivo and in WRL-68 cells in vitro, but not in cancer cells in vivo or in vitro. J Integr Med 12: 425-438, 2014.

16. Wang YH, Qiu C, Wang DW, Hu ZF, Yu BY and Zhu DN: Identification of multiple constituents in the traditional Chinese medicine formula Sheng-Mai San and rat plasma after oral administration by HPLC-DAD-MS/MS. J Pharm Biomed Anal 54: 1110-1127, 2011.

17. Thompson CB: Apoptosis in the pathogenesis and treatment of disease. Science 267: 1456-1462, 1995.

18. Mohamad N, Gutiérrez A, Núñez M, Cocca C, Martín G, Cricco G, Medina V, Rivera E and Bergoc R: Mitochondrial apoptotic pathways. Biocell 29: 149-161, 2005.
19. Lucken-Ardjomande S and Martinou JC: Newcomers in the process of mitochondrial permeabilization. J Cell Sci 118: 473-483, 2005

20. Ott M, Gogvadze V, Orrenius S and Zhivotovsky B: Mitochondria, oxidative stress and cell death. Apoptosis 12: 913-922, 2007.

21. Götz ME, Künig G, Riederer P and Youdim MB: Oxidative stress: Free radical production in neural degeneration. Pharmacol Ther 63: 37-122, 1994.

22. Cagnol S and Chambard JC: ERK and cell death: Mechanisms of ERK-induced cell death-apoptosis, autophagy and senescence. FEBS J 277: 2-21, 2010

23. Kralova J, Dvorak M, Koc M and Kral V: P38 MAPK plays an essential role in apoptosis induced by photoactivation of a novel ethylene glycol porphyrin derivative. Oncogene 27: 3010-3020, 2008.

24. Dhanasekaran DN and Reddy EP: JNK signaling in apoptosis. Oncogene 27: 6245-6251, 2008. 